\title{
Seeking clarity in the twilight zone ${ }^{\dagger}$ COMMENTARY ON... ADOLESCENT DECISION-MAKING AND THE ZONE OF PARENTAL CONTROL
}

\author{
Aaron K. Vallance
}

\begin{abstract}
SUMMARY
This commentary offers further arguments relating to the ambiguities inherent in the new concept of the zone of parental control (ZPC) as defined by the revised Mental Health Act Code of Practice, but argues that a directive approach needs to be balanced with flexibility. The conflicting rights of child, parent and State are also discussed. Whereas medico-legal discourse tends to base itself on previous legislative frameworks, it is argued that an evidence-based approach may also be valuable in order to ascertain and incorporate young people's views on the matter.
\end{abstract}

\section{DECLARATION OF INTEREST}

None.

Throughout human history, societies traditionally mark children's coming of age with new duties and opportunities. Such transitions resonate in modern secular societies, which use legislation to confer developed levels of maturity with additional rights and responsibilities, for example sexual consent, marriage, criminal responsibility and film age ratings. Age and maturity likewise feature in legislation governing the individual's right to make healthcare decisions.

In England, various legislative frameworks and case law proceedings bear influence when children make decisions about their healthcare. With regard to their mental healthcare, further legislation comes into consideration with the revised Mental Health Act Code of Practice (Department of Health 2008). Akerele (2014, this issue) highlights the Code of Practice's new concept of the zone of parental control (ZPC), used to define criteria to help professionals decide whether parents can consent on behalf of their child, for example for an under-16-year-old lacking competence and/ or refusing treatment or admission. Previously, despite the tone set by 'Gillick competence' (Gillick $v$ West Norfolk and Wisbech Area Health Authority 1986), case law such as $R e R$ [1992] and Re $W$ [1992] has meant that parental consent could be sufficient for psychiatric treatment or hospital admission of a child (Paul 2004). Now, if a situation is deemed 'beyond' the ZPC, clinicians should consider the Mental Health Act 1983, as amended in 2007, or Court proceedings instead.

\section{Criticisms of the MHA Code of Practice}

Akerele critiques the revised Code of Practice on three grounds. First, that the guidelines are ambiguous and lack detail, and should be more directive. Second, that the power shift from parents towards the State may pose disadvantages. Third, that changes should have been enshrined in statutory legislation to allow a deeper enquiry, a more robust basis and to give it more 'teeth'. This commentary will focus on the first two points.

\section{The guidelines are ambiguous, lack detail and should be more directive}

Further arguments can be made on the ZPC's ambiguity. For example, a 'decision [...] that a parent would be expected to make [in accordance with] normal practice in our society' (Akerele 2014) begs the question of what is 'normal'. A study by DuràVilà $\&$ Hodes (personal communication, 2014) on adults' attitudes towards children's capacity to consent to various medical interventions (including psychiatric admission) reveals significant disparity across different religious/ethnic communities. Another questionable criterion is that the 'more extreme the intervention, the more likely it will fall outside the ZPC' (Akerele 2014). This arguably conflicts with the 'normal practice in society' criterion, since most parents would 'normally' expect to be more, not less, involved in their child's decision-making the more extreme the intervention.

Akerele's argument on clarity begs the question of what directive guidance should look like. The risk could be greater restrictiveness. Johnston's (2009) qualitative study reflects that professionals may prefer flexibility over a tick-box algorithm when dealing with adolescent decision-making. One possibility could involve the construction of example scenarios, particularly as case law accumulates (Bowers 2010).
Aaron K. Vallance is a consultant in child and adolescent psychiatry with the Southwest Surrey Child and Adolescent Mental Health Service (Surrey and Borders Partnership NHS Foundation Trust) and a clinical senior lecturer in the Faculty of Medicine (Faculty of Education) at Imperial College London. His specialist interests include medical education and writing on various clinical aspects of child and adolescent psychiatry. Correspondence Dr Aaron K. Vallance, Southwest Surrey CAMHS Community Team, Bray Road, Guildford GU2 7L0, UK. Email: aaron.vallance@sabp.nhs.uk

\footnotetext{
${ }^{\dagger}$ See pp. 144-150, this issue.
} 


\section{The power shift from parents to the State}

Akerele's reflections also illustrate the involvement of three key stakeholders - the child, the parents and the State - and that tensions can arise as to who ultimately is in authority. The United Nations Convention on the Rights of the Child (UNCRC) and the Children Act 2004 emphasise that, insofar as is possible, children should be centrally placed when decisions need to be made about them. This proviso reflects the explicit recognition that immaturity (and mental disorder) may challenge a child's capacity for decision-making. However, deciding on whether a competency threshold is crossed can be difficult and subjective. Neurobiological research reveals that maturation of brain regions associated with higher cognitive functioning continues well into adulthood (Blakemore 2006). Professionals may also judge that, although a child may appear to attain some maturity, accepting an adolescent's competence to refuse intervention can be challenging, given their 'lack of life experience, settled values and the ability to project into the future' (Johnston 2009).

Legislation such as the UNCRC and the Children Act generally unite on the principle that there exist situations when another authority may need to decide on behalf of a child, and that the principle of the child's best interests should be used. The question remains as to who should exert this authority. On one hand, the UNCRC confers rights to parents, who are deemed to be central to their children's well-being. On the other, as Iltis (2010) argues, the UNCRC effectively places parents in the role of guides to help children in making their life choices, whereas the State is cast as the ultimate guardian to protect children's interests.

Against a backdrop of different frameworks and case law proceedings, each with its own positioning of the parent-State balance, the revised Code of Practice arguably shifts power away from parents and towards the State. However, Iltis (2010) argues that the UNCRC itself places too much emphasis on the State, asserting that parents: are generally closest to situations involving their children; will account for other family members' needs; and have financial and physical responsibility for their children. Likewise, Paul (2004) argues that parents' views occasionally need to be prioritised to prevents significant harm or undermining of their ability to maintain their family. In contrast, an Eriksonian stance may argue against such parental control and towards adolescent individuation instead (Erikson 1968).

Like Iltis (2010), Akerele points to the potential harm of State intervention, for example the stigma and impact on future prospects experienced by people who have been subject to detention or treatment under the Mental Health Act. In light of the UK government's recent 'zero-harm' drive (Illman 2013), it becomes particularly incumbent on clinicians to minimise risk. Akerele notes that the Mental Health Act does, however, confer legal safeguards, such as right to appeal.

When considering the pros and cons of parental consent versus the law, surely a key factor - in keeping with UNCRC - is the view of the young person concerned in the particular case. However, more generally, a significant step forwards would see research to ascertain young people's views on the matter in general. Medico-legal discourse puts much currency in established medico-legal frameworks, which are themselves open to question; for example, Iltis (2010) argues that the UNCRC is fundamentally compromised in its attempts to reach consensus across disparate nations. Case law, meanwhile, is based on a handful of cases, which may only partially resemble the case at hand. Indeed, as Akerele notes, only one case in the European Court of Human Rights (Nielsen v Denmark 1989) influenced the Code of Practice, and that pertained to a different country. Perhaps the medico-legal system may therefore benefit from the path taken by clinical interventions in incorporating more of the evidence base in its practice.

\section{References}

Akerele F (2014) Adolescent decision-making and the Zone of Parental Control: a missed opportunity for legislative change. Advances in Psychiatric Treatment, 20: 144-50.

Blakemore S, Choudhury S (2006) Development of the adolescent brain: implications for executive function and social cognition. Journal of Child Psychology and Psychiatry, 47: 296-312.

Bowers M, Dubicka B (2010) Legal dilemmas for clinicians involved in the care and treatment of children and young people with mental disorder. Child: Care, Health and Development, 36: 592-6.

Department of Health (2008) Code of Practice: Mental Health Act 1983. Published Pursuant to Section 118 of the Act. TSO (The Stationery Office). Erikson EH (1968) Identity: Youth and Crisis. W. W. Norton.

IIIman J (2013) Obama adviser to make 'zero harm in the NHS a reality', pledges PM. Health Service Journal, 6 Feb.

Iltis AS (2010) Toward a coherent account of pediatric decision making. Journal of Medicine and Philosophy, 35: 526-52.

Johnston C (2009) Overriding competent medical treatment refusal by adolescents: when 'no' means 'no'. Archives of Disease in Childhood, 94: 487-91.

Paul M (2004) Decision-making about children's mental health care: ethical challenges. Advances in Psychiatric Treatment, 10: 301-11.

Gillick v West Norfolk and Wisbech Area Health Authority [1986] AC 112. Nielsen v Denmark (App no 10929/84) (1989) 11 EHRR 175.

Re R (A Minor) (Wardship: Consent to Treatment) [1992] Fam 11 CA. Re W(A Minor) (Medical Treatment: Court's Jurisdiction)[1992] 3 WLR 758. 